\title{
Remembering in California sea lions: Using priming cues to facilitate language-like performance
}

\author{
RONALD J. SCHUSTERMAN \\ University of California, Santa Cruz, California \\ and California State University, Hayward, California \\ and \\ EVELYN HANGGI and ROBERT C. GISINER \\ University of California, Santa Cruz, California
}

\begin{abstract}
Two sea lions (Zalophus californianus) were trained to respond to relational commands by bringing the last designated object (transport item, or TD) to the earlier designated object (goal item, or GI). Most errors on this task involved forgetting of the GI due to interference from memory for the TI. We reasoned that instructing the animals to act directly on the same object several times in single-object commands immediately before a relational command that included the same object as the GI should make the GI associative episode less prone to interference by the TI associative episode. Results confirmed that prior cuing or prompting in this manner did enable the sea lions to perform significantly better on relational commands when no cuing was given.
\end{abstract}

Dating back to the volume by Honig and James (1971) and the review by D'Amato (1973), investigations of animal memory have become extensive enough to result in several recent journal reviews (cf. Kamil \& Roitblat, 1985; Roitblat \& Von Fersen, 1992; Shettleworth, 1990; Spear, Miller, \& Jagielo, 1990) as well as a broad range of edited books devoted largely or exclusively to this topic (Kendrick, Rilling, \& Denny, 1986; Roitblat, Bever, \& Terrace, 1984; Spear \& Miller, 1981; Weinberger, McGaugh, \& Lynch, 1985). For the most part, this research and theorizing has fallen within the context of a general processes approach to animal memory (see Rilling \& Neiworth, 1986).

In the general processes approach, forgetting of the tobe-remembered stimuli is heightened when either preceding or subsequent stimulus conditions modify the animal's performance on a retention test (cf. Wright, Urcuioli, \& Sands, 1986; Wright, Urcuioli, Sands, \& Santiago, 1981). The disrupting effects of preceding or subsequent stimulation on the retention of the to-be-remembered stimulus

The experiment reported in this paper was funded by Contract N0001485-K-0244 from the Office of Naval Research to R.J.S. We very much appreciate the enthusiastic efforts put forth by several student assistants. Brigit Grimm and Rebecca Hardenbergh played major roles in helping to conduct the experiment and supervising student assistants. We thank Peter Urcuioli and one anonymous referee for thorough reviews of earlier manuscripts. The experiment was first described orally at the Animal Behavior Society meeting in Missoula, MT, August 7-13, 1988. R.J.S. is affiliated with the Long Marine Laboratory at Santa Cruz, as is E.H. and as was R.C.G. at the time of this research. R. C. Gisiner is currently with the Naval Ocean Systems Center, Kailua, HI 96734 . Reprints may be obtained from R. J. Schusterman, Department of Psychology, California State University, Hayward, CA 94542. are called proactive and retroactive interference, respectively. In birds and mammals, reestablishing relations that have been disrupted by interference suggests that most cases of forgetting reflect difficulty in retrieval and expression following the retention interval rather than problems during the earlier processes of encoding, attention, and association (Spear, 1981). Moreover, research on cuedependent learning and remembering indicates that the greater the similarity between the current retrieval cues and the conditions or circumstances under which the information has originally been acquired, the greater the probability that remembering will occur (Tulving, 1974).

In previous reports (see Gisiner \& Schusterman, 1992; Schusterman \& Gisiner, 1988; Schusterman, Gisiner, Grimm, \& Hanggi, 1993; Schusterman \& Krieger, 1984, 1986), we showed that in language-like learning tasks similar to symbolic delayed matching-to-sample (DMTS), California sea lions (Zalophus californianus) could be trained to organize their responses to comparison objects according to two different types of rules transmitted in the form of gestural sign sequences by a human signaler. The sea lions were trained first on a single-object sequence and taught to act directly on one object when there were many available comparison objects to choose from (e.g., white pipe under = "duck under the white pipe" or water tail-touch = "place your tail to water jetted from a hose into the tank"). The sea lions were trained on the relational sequence later and taught to relate two objects (again where there were several to choose from) by taking one object to another (e.g., large cone, black bat fetch = "take the black bat over to the large cone"). In the relational instruction, the second object signaled, the black plastic baseball bat, was the transport item (TI), and the 
first object signaled, the large plastic traffic cone, was the destination or goal item (GI).

As these examples of sign combinations show, there were three classes of signs: actions $(A)$, objects $(O)$, and modifiers (M). To train the sea lions to respond to the relational command, we imposed an added conditional relation to responses indicated by $\mathrm{O}-\mathrm{A}$ sign combinations (see Schusterman \& Gisiner, 1988; Schusterman \& Krieger, 1984). Relational instructions were formed by the addition of a second object sign (with optional modifiers) to a fetch object-action pairing. In this way, we changed a single-object, nonrelational instruction like ring fetch (O-A) ("fetch the ring" to the signaler) to a relational instruction like pipe, ring fetch (O-O-A) ("take the ring to the pipe") or ring, pipe fetch ("take the pipe to the ring").

The relational combination had been introduced to add structural complexity to the artificial language because, with single-object combinations, the signs alone, regardless of their order, were sufficient to indicate which object should be acted on (Gisiner \& Schusterman, 1992; Schusterman \& Gisiner, 1989). In relational combinations, the relationships between the signs add information not conveyed by the signs alone. Thus pipe, ring fetch becomes a different instruction from ring, pipe fetch, because of the changed relationship between the signs (Gisiner \& Schusterman, 1992; Herman, 1986; Schusterman \& Gisiner, 1988). This type of relational stimulus command has been successfully taught to two species of marine mammals: California sea lions (Zalophus californianus) and bottlenose dolphins (Tursiops truncatus). However, both types of marine mammals performed significantly worse on a relational instruction than on a nonrelational instruction. Moreover, both Zalophus and Tursiops have relatively little difficulty in selecting the signaled TI; they have much greater difficulty in selecting the signaled GI (e.g., see Table 9 in Schusterman \& Gisiner, 1988, and see Table 10.3 in Herman, 1986).

It has been suggested that, for both types of marine mammals, reception of the signs designating the $\mathrm{TI}$, as well as searching and then swimming to the TI, has a disrupting effect on the retention of the GI, which is signaled prior to the sign designating the TI (Herman, 1986; Schusterman \& Gisiner, 1988, 1989). Selection of the TI and its transportation can be thought of as a task interpolated between the time when the GI signal is given and the time when the final choice of the GI is made. In other words, as the animals relate the subsequent signals to a second item and prepare to respond to it (TI), there may be retroactive interference on the retention of the initially signaled item (GI).

The issue we addressed in the present experiment was whether initial priming or prompting of the signaled GI in relational commands could make the "forgotten" signobject association expressible-that is, make the memory of the GI associative episode more active and, therefore, less subject to interference by the TI associative episode. Regardless of the type and number of objects available, sea lions average about $95 \%$ correct responses on single- object commands and show comparable performance levels in choosing the signaled $\mathrm{TI}$ on relational commands. But, as previously noted, the choice of appropriate Gls is much less probable, and correct responses to relational instructions depend to a large degree on the type (object shape, size, and brightness) and number of GIs available (Schusterman \& Gisiner, 1988, 1989). In this study, we hypothesized that instructing sea lions to act directly on the same object (e.g., a black ball) several times in single-object commands prior to being given a relational command containing the same object (black ball) as the GI should enhance memory for the GI associative episode and, therefore, make it less prone to interference by the TI associative episode. This hypothesis was derived from the study of cue-dependent learning and retention, which demonstrates that the closer conditions are to original learning (the sea lions were trained on the single-object sequence before the relational sequence), the greater the probability that the learner will show remembering (for reviews, see Spear et al., 1990, and Tulving, 1974).

Note that priming in the present experiment should be distinguished from the way the term "prior cuing" is used by Spear (1981). The sequence in our paradigm hypothesized to facilitate retention of the GI associative episode consisted of priming, associative cues, interference, and testing. Spear characterizes the sequence of events in the prior cuing paradigm as initial learning, retention interval, prior cuing, and testing.

\section{METHOD}

\section{Subjects, Apparatus, and Baseline Procedure}

The experiment, which began in September 1987 and lasted 6 months, involved 2 adult female California sea lions. Rocky, who was approximately 11 years old when we began the study, had nearly 6 years of experience with her artificial language, the last 2 of which included relational commands. Gertie, who was 5 years old when the experiment started, had 3 years of experience with her artificial language, including 1 year with relational commands. Descriptions of the tank in which the sea lions were housed, trained, and tested, and descriptions of most of the objects and individual signs, as well as procedures for presenting sign combinations and recording responses by Rocky and Gertie, can be found in Schusterman and Krieger $(1984,1986)$, Schusterman and Gisiner (1988), and Gisiner and Schusterman (1992). The sea lions received $3-4.5 \mathrm{~kg}$ of cut fish (herring and smelt) daily as rewards.

For Rocky, the numbers of potential sign combinations included in single-object and relational commands were 844 and 6,223, respectively. The single-object commands included $76 \mathrm{O}-\mathrm{A}$ combinations and $768 \mathrm{M}-\mathrm{O}-\mathrm{A}$ and $\mathrm{M}-\mathrm{M}-\mathrm{O}-\mathrm{A}$ combinations. Relational commands contained sign combinations ranging in length from three to seven, depending on whether there were modifiers associated with the GI and TI. For Gertie, the number of potential sign combinations included in single-object and relational commands were 100 and 274 , respectively. The single-object commands included $40 \mathrm{O}-\mathrm{A}$ combinations and $60 \mathrm{M}-\mathrm{O}-\mathrm{A}$ combinations. Relational commands for Gertie contained sign combinations ranging in length from three to five, depending on whether or not there were modifiers associated with the GI and TI. From their entire corpus of sign combinations, Rocky and Gertie received a different randomized set of about 50-70 combinations each day (about 5 days 
per week) as baseline training and maintenance sessions. For Rocky (but not Gertie), these occasionally included novel relational sign combinations - combinations that the sea lion had never been given before.

Each session consisted of blocks of from four to eight trials in all of which the same group of objects was used. After each block, the objects were replaced with a new group of objects. For Rocky, there were typically 4-10 objects available in each block; for Gertie, 3-10 objects were available. Only a completely correct performance was reinforced. For example, if a sea lion selected an appropriate TI but the wrong GI on a relational instruction, or if the sea lion selected the appropriate object but used an inappropriate action on a single-object instruction (flipper touch when signed under), the performance was not reinforced.

\section{Sea Lions' Responses to Sign Sequences}

A typical relational sequence for Rocky is illustrated in Figure 1. A signal sequence started with Rocky on station, her chin resting on the signaler's foot (not shown). The first sign and each subsequent sign in a sequence were cued by an observer who told the blindfolded signaler (via radio headphones) that Rocky was in position to receive the next sign. Rocky typically left station after an object signal, visually searched for the object (A and D), and, after locating it, returned to station (B). She did not leave station or scan the pool area after modifier signals $(C)$. Because the sea lion's eyes are aimed primarily forward and up, it must essentially point with its head in order to bring the object into the field of focused binocular vision. Following orientation to the object black ring (D) and subsequent restationing, Rocky was given the fetch signal (E). In panel $F$, Rocky can be seen completing the relational instruction by bringing the black ring to the Clorox bottle.

Gertie's signal sequence (Figure 2) differed from Rocky's in several ways. First, Gertie was not given a gestural sign for an object, but was instead shown another object. The object shown Gertie was in most cases the same as the one in the pool (a match); but for three of the objects, the object shown was only symbolically related to the referent-that is, it did not share any obvious properties of the object it indicated. For example, water was indicated by the presentation of a white disk. The brightness modifier (black/white) was contained in the object presentation, unlike in Rocky's procedure, in which separate modifier signs preceded an object sign and were subsequently integrated by Rocky in the performance of her response. Second, unlike Rocky, Gertie did not spontaneously leave station to search for an object after receiving
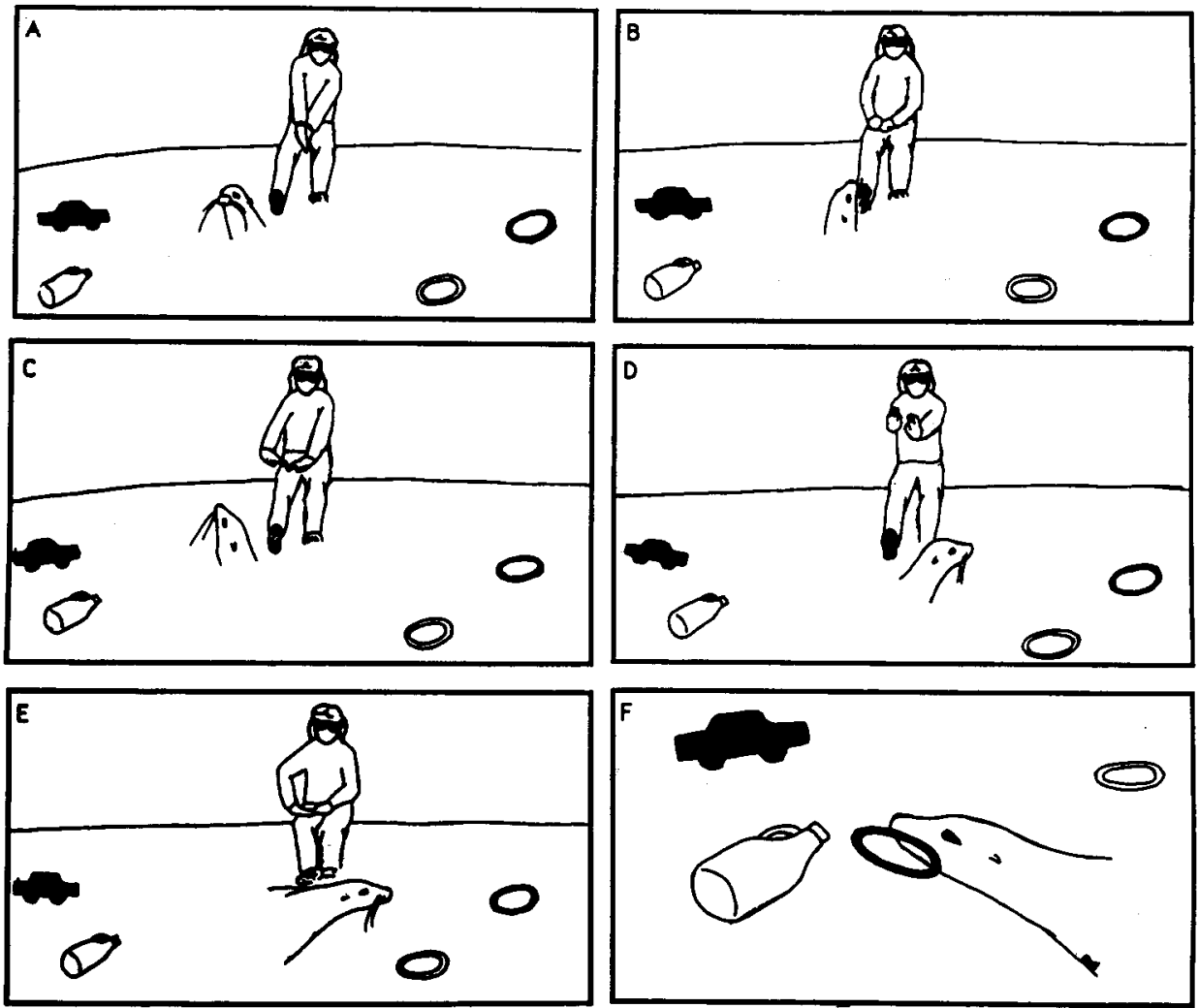

Figure 1. An illustration of a relational command given to sea lion Rocky and her subsequent correct performance. The instructional sequence was bottle, black ring fetch. (A) The trainer gives the gestural sign or conditional cue bottle (the goal item, or GI), and, after a visual search, Rocky orients herself to the object. (B) Following orientation to the GI, Rocky re-stations on the trainer's foot while the latter pauses before signaling the transport item (TI). (C) The modifier sign black is given; Rocky turns slightly but does not scan the pool area. (D) The signaler gives the ring sign, and, after brienly looking at the white ring, Rocky orients herself to the signaled black ring and then re-stations again. (E) The action sign fetch has been given and Rocky has been released (signaler lowers foot). (F) Rocky has gone to the black ring and moved it while scanning the pool for the GI. In this frame, Rocky is placing the black ring in contact with the bottle. 


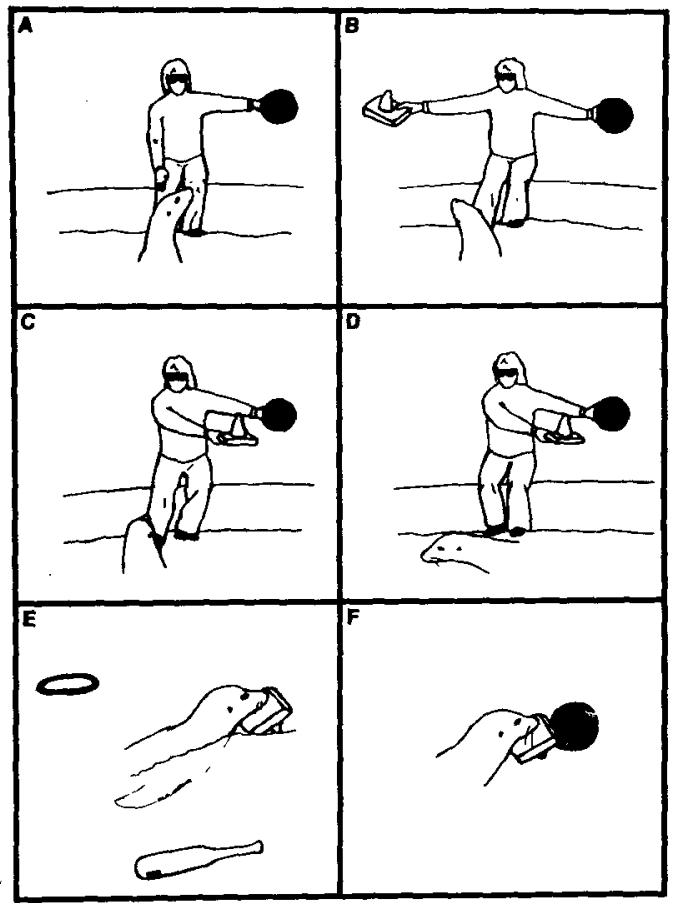

Figure 2. An illustration of a relational command given to sea lion Gertie and her subsequent correct performance. The instructional sequence was ball, white cone fetch. (A) Signaler presents an object that serves as the conditional cue for the GI (bail). (B) Signaler presents the second object with the right hand-in this case, a white cone that serves as an instructional cue for the TI (white cone) floating on the pool surface. (C) Signaler brings the second object over to the first. This gestural sign indicates the relational fetch action. (D) Gertie has been released from station by the signaler lowering her foot. (E) Gertie pushes the TI (white cone) past other comparison objects. (F) Gertie successfully completes the relational command by bringing the white cone to the ball.

the object sign. Third, Gertie's relational fetch sign differed from her single-object fetch sign. Rocky's relational fetch sign was the same as her single-object fetch sign; only the context of the preceding one (single-object fetch) or two (relational fetch) object signs differentiated the two meanings. In Gertie's language, objects designate other objects, so relational instructions were given by first presenting (with an extended left arm) the object designating the GI (Figure 2, panel A), and then presenting the second object designating the $\mathrm{TI}$ in the right hand (Figure 2, panel B). The trainer then moved the object in his/her right hand toward the object in the other hand until they were close together or touching (Figure 2, panel $C$ ). The trainer then released Gertie to perform the relational action (Figure 2, panels D, E, and F). Finally, for Gertie but not for Rocky, some of the objects could be located on the deck around the pool, as well as in the water.

\section{Experimental Design}

Priming sets. Each sea lion served as its own control. We analyzed performance on relational commands as a function of either no prior cuing (control) or two and four prior cues (primes) of the same designated object during single-object commands.

A priming set included a relational command preceded by two or four single-object commands referring to the object designated as the GI in the subsequent relational command (see Table 1 for examples). A priming sequence was signaled as follows: Following an $\mathrm{O}-\mathrm{A}$ or $\mathrm{M}-\mathrm{O}-\mathrm{A}$ sign combination, the sea lion was released from station, acted correctly to the command, and was reinforced. Following the priming trials, the trainer signaled a relational command in which the GI was the same object as the one that had been designated in the preceding single-object commands. A correct response consisted of the signaled TI's being brought to the primed GI. Although TI errors rarely occurred on relational tests, if one did occur, the whole priming set was repeated following one or two intervening baseline sets. Each priming set consisted of four to eight trials, including the relational test trial preceded by zero to four priming trials; it also included an occasional single-object command referring to a nonprimed object. Gertie's priming sets always had four objects for her to choose from; Rocky's always had six. Priming sets contained either a two- or a four-prime relational test, or a relational test that had no primes (zero prime). On each testing day, either a two- or a four-prime relational set was run along with a zero-prime relational set, interspersed among the baseline sets described earlier.

To minimize the influence of such variables as object preferences (see below, and see Schusterman \& Gisiner, 1988, 1989), motivation of the sea lions, weather conditions, and so forth, daily relational tests (control and primed) had the same designated GI. For this reason, we controlled for sequence effects by running the twoor four-prime relational set prior to the zero-prime relational set on half the daily test sessions and the opposite sequence on the other half of the daily test sessions. There were always at least four baseline sets between a priming set and a zero-prime (control) set. In this manner, performance on the zero-prime relational tests served as a control against which performance on two- and four-prime relational tests could be compared and statistically tested.

As far as wind and water movement allowed, the object to be primed was kept in a similar location for both the single-object priming commands and the subsequent relational test trial. The time between trials varied randomly, and it generally ranged from 11 to $39 \mathrm{sec}$.

Rocky received 40 two-prime and 40 four-prime relational tests along with 80 control or zero-prime relational tests; Gertie received 30 two-prime and 30 four-prime relational tests along with 60 control tests. Since repetition of the same single-object commands had a relatively low probability during earlier baseline sets, an equal number of "bogus" priming sets was given (i.e., the same singleobject commands were repeated) without a subsequent relational test, in order to minimize the animals' anticipation of a relational command's following a priming sequence. Therefore, it is unlikely that when a relational test began, the subjects knew which signal would be used to designate the GI until it was presented. In summary, then, a priming set included a relational command preceded by zero, two, or four single-object commands referring to the object that was designated as the GI in the subsequent relational instruction (see Table 1 for examples).

Preferred and nonpreferred GIs. Rocky and Gertie appeared to have preferences for objects serving as a $\mathrm{GI}$ in relational commands. An object was considered to be preferred if the sea lions responded correctly on $50 \%$ or more of the baseline relational trials in which that object was the GI. To avoid biases toward preferred objects and prevent a ceiling effect in relational performance, we used only nonpreferred objects as GIs in priming sets. Since the preferred/nonpreferred statusi of an object as a GI changed over time (see Schusterman \& Gisiner, 1988), the GI preference status of each object was updated three times during the course of the experiment. Controlling for object preferences reduced Rocky's 35 potential GIs in priming sets to $21-25$ and reduced Gertie's 14 potential GIs to 9-11.

Calculating performance levels for relational instructions. After learning the relational command, the sea lions Gertie and Rocky erred almost solely on the GI (see Schusterman \& Gisiner, 1988). They rarely failed to go to the correct TI or to take the TI to another object (correct action), but they often took the TI to an object other than the GI indicated by the signaler. We therefore 
Table 1

Examples of Zero-, Two-, and Four-Prime Relational Tests

\begin{tabular}{|c|c|c|}
\hline $\begin{array}{c}\text { Number of Primes Preceding } \\
\text { Relational Test }\end{array}$ & Example & Trial Type \\
\hline 0 & $\begin{array}{l}\text { pipe, large cube fetch } \\
\text { small black cone under } \\
\text { small black cone mouth } \\
\text { small black cone, white ring fetch } \\
\text { white ball tail touch } \\
\text { white ball flipper touch } \\
\text { white ball fetch } \\
\text { white ball over } \\
\text { white ball, football fetch }\end{array}$ & $\begin{array}{l}\text { relational } \\
\mathrm{O}-\mathrm{M}-\mathrm{O}-\mathrm{A} \\
\text { single object } \\
\mathrm{M}-\mathrm{M}-\mathrm{O}-\mathrm{A} \\
\text { single object } \\
\mathrm{M}-\mathrm{M}-\mathrm{O}-\mathrm{A} \\
\text { relational } \\
\mathrm{M}-\mathrm{M}-\mathrm{O}-\mathrm{M}-\mathrm{O}-\mathrm{A} \\
\text { single-object } \\
\mathrm{M}-\mathrm{O}-\mathrm{A} \\
\text { single object } \\
\mathrm{M}-\mathrm{O}-\mathrm{A} \\
\text { single object } \\
\mathrm{M}-\mathrm{O}-\mathrm{A} \\
\text { single object } \\
\mathrm{M}-\mathrm{O}-\mathrm{A} \\
\text { relational } \\
\mathrm{M}-\mathrm{O}-\mathrm{O}-\mathrm{A}\end{array}$ \\
\hline
\end{tabular}

made the probability of a completely correct response dependent on the number of objects in the pool available to serve as GIs. The probability that Rocky or Gertie would go to the correct TI and take it to another object was nearly 1.0 . Selection of an object to serve as the GI, if the sea lions were choosing at random, would thus be a function of the number if objects in the pool less one (the object used as a TI). If there were six objects in the pool, five would be available for use as the GI, and the sea lion would have a one-in-five $(0.20)$ chance of taking the TI to the correct GI by chance alone. For a single trial, therefore, the probability of a chance correct response was calculated as $1 /(x-1)$, where $x$ equals the number of objects in the pool.

\section{RESULTS}

As Table 2 indicates, prior cuing of the GI increased the percentage of complete correct responses to relational commands significantly above that expected by chance alone for both sea lions. Indeed, without priming of the GI, Gertie (but not Rocky) performed no better than was expected by chance. Each animal showed nearly the same level of performance, regardless of whether cuing of the GI occurred two or four times prior to their being given the relational instructions.

The matched-pairs design of the experiment enabled us to compute the number of effective primes by comparing each sea lion's daily test performance on the primed relational commands to the zero-prime (control) relational commands. The statistical analysis (sign test, one tail) indicated a positive effect for both subjects when two- and four-prime trials were combined and compared with the corresponding control trials. The priming for Gertie was effective on 23 of 30 comparisons ( $p=.01$ ), with 30 ties; for Rocky, GI priming was effective on 21 of 31 comparisons $(p=.05)$, with 49 ties.

Table 3 shows that Rocky's performance on relational tests was generally comparable on sign combinations that were novel versus familiar, and her performance did not vary consistently as a function of the number of signs contained in a relational command. Therefore, the main variable affecting Rocky's performance on relational commands was prior cuing of the GI by single-object commands.

\section{DISCUSSION}

During the past two decades, the DMTS procedure has been commonly used for studying short-term memory in a variety of animal taxa (Spear et al., 1990). Usually the subject is first presented with the to-be-remembered conditional cue (sample), which is followed by a retention

Table 2

Performance of Two California Sea Lions on Relational Sequences

Following Zero (Control), Two, or Four Primes of the Goal Item (GI)

\begin{tabular}{|c|c|c|c|c|c|c|c|c|}
\hline & \multicolumn{8}{|c|}{ Number of GI Primes } \\
\hline & \multicolumn{4}{|c|}{ Rocky } & \multicolumn{4}{|c|}{ Gertie } \\
\hline & 0 & 2 & 4 & $2+4$ & 0 & 2 & 4 & $2+4$ \\
\hline Number of trials & 80 & 40 & 40 & 80 & 60 & 30 & 30 & 60 \\
\hline Correct responses & 25 & 17 & 19 & 36 & 18 & 18 & 16 & 34 \\
\hline$\%$ correct responses & 31.2 & 42.5 & 47.5 & 45.0 & 30.0 & 60.0 & 53.3 & 56.7 \\
\hline$\%$ expected & 20.0 & 20.0 & 20.0 & 20.0 & 33.3 & 33.3 & 33.3 & 33.3 \\
\hline Chi-square & $6.3^{*}$ & $12.7 \dagger$ & $18.9 \dagger$ & $31.3 \dagger$ & 0.3 & $9.6 \dagger$ & $5.4 *$ & $14.7 \dagger$ \\
\hline
\end{tabular}

${ }^{*} p<.05$, two-tailed test. $\dagger p<.01$, two-tailed test. 
Table 3

Rocky's Performance on the Priming Experiment as a Function of Number of Signs Per Relational Sequence and Novel Combinations

\begin{tabular}{|c|c|c|c|c|c|}
\hline \multirow{3}{*}{$\begin{array}{l}\text { Number } \\
\text { of Signs }\end{array}$} & & \multicolumn{4}{|c|}{ Number of GI Primes } \\
\hline & & \multicolumn{2}{|c|}{0} & \multicolumn{2}{|c|}{$2+4$} \\
\hline & & Familiar & Novel & Familiar & Novel \\
\hline 3 & $\begin{array}{l}\text { Total trials } \\
\text { Correct responses } \\
\% \text { correct responses }\end{array}$ & $\begin{array}{l}46 \\
15 \\
32.6\end{array}$ & & $\begin{array}{l}48 \\
21 \\
43.8\end{array}$ & \\
\hline 4 & $\begin{array}{l}\text { Total trials } \\
\text { Correct responses } \\
\% \text { correct responses }\end{array}$ & $\begin{array}{c}25 \\
8 \\
32.0\end{array}$ & $\begin{array}{c}15 \\
6 \\
40.0\end{array}$ & $\begin{array}{l}24 \\
12 \\
50.0\end{array}$ & $\begin{array}{c}15 \\
7 \\
46.7\end{array}$ \\
\hline 5 & $\begin{array}{l}\text { Total trials } \\
\text { Correct responses } \\
\text { \% correct responses }\end{array}$ & $\begin{array}{c}9 \\
2 \\
22.2\end{array}$ & $\begin{array}{c}7 \\
2 \\
28.6\end{array}$ & $\begin{array}{c}8 \\
3 \\
37.5\end{array}$ & $\begin{array}{c}5 \\
3 \\
60.0\end{array}$ \\
\hline
\end{tabular}

or delay interval that varies from a fraction of a second to several minutes. In symbolic matching, the subject is then required to select a comparison stimulus that is arbitrarily related by earlier associative learning to the previously presented sample. Accurate performance depends, among other things, on remembering a coded representation of the sample, since it is absent when a comparison choice is made. The coding might be accomplished by maintaining a representation of the sample stimulus in memory (retrospective coding) and/or a representation of the related comparison stimulus (prospective coding).

In the present context, we assume that components of arbitrary DMTS procedures are contained in single-object $(\mathrm{O}-\mathrm{A})$ and relational $(\mathrm{O}-\mathrm{O}-\mathrm{A})$ commands, each with one or more conditional cues (gestural signals) associated with one or two objects (the comparison stimuli), respectively. Delay intervals from the time when the signals associated with an object were given to the time when an object was selected or oriented to by a sea lion varied from fractions of a second to about $10 \mathrm{sec}$. Therefore, in relational commands, the sea lions' reactions to signals referring to the TI can be considered a task interpolated during the time interval separating signals referring to the GI (including orientation by Rocky but not by Gertie) and subsequent selection of a GI (see Figures 1 and 2).

Emphasizing DMTS as a model of working memory, several investigators have presented interpolated stimuli into the retention interval and found a significant decrement in choice accuracy in pigeons and nonhuman primates. (See Wright et al., 1981, and Spear et al., 1990, for critical reviews and attempts to clarify whether performance deficits due to interpolated stimulation reflect forgetting or confusion in animal subjects.) In nonverbal animals, as in humans, if forgetting is due to retroactive interference, information must rapidly be lost from shortterm memory unless maintained there through rehearsal (Kendrick \& Rilling, 1986).

The present experiment with California sea lions was designed, within the context of using a task interpolated during the delay interval of a symbolic DMTS, to answer the following question: In a language-like test in which signs associated with objects and actions are given sequen- tially, can the disruptive influence of a recent associative episode (the interpolated TI task) on an earlier associative episode (the targeted GI), be alleviated by repeated, prior activation of the earlier associative episode? The answer is yes, since priming of the GI by multiple singleobject commands enabled the sea lions to perform significantly better on relational commands than in matched control trials involving no such prior cuing. We interpret the effects of the single-object primes as a way of buffering or preserving the memory of the GI associative episode from the retroactive interference of the more recent TI associative episode. Thus, by maintaining a more active representation of the GI than had occurred during their baseline performances, Rocky and Gertie were each able to express their memory for the GI more consistently on a primed relational task.

One might look for behavioral correlates of the postulated cognitive mechanisms. These behaviors would be expected to be directly related to the single-object instructions, which generated repeated (food-reinforced) active search patterns of the pool area in which the GI on the subsequent relational test was most likely to be. Consequently, priming might have enabled the sea lions to restrict their search area and thus diminished the time to locate the GI, in relation to the time that this took on the unprimed control trials. However, a review of video tapes of the relational test trials revealed no such trends. Indeed, detailed analysis of Rocky's swim and search patterns (not all of Gertie's sessions were tape-recorded) showed the opposite. Rocky's selections of a GI following the choice of a TI actually took more time $(M=$ $5.9 \mathrm{sec} \pm 2.2$ ) following primed trials than following matched control trials $(M=5.2 \mathrm{sec} \pm 2.3)$; the difference is statistically significant $[t(38)=2.03, p<.05$, two-tailed]. These data argue against the notion that priming simply resulted in a restricted search for the GI. On the contrary, there was a greater tendency for a subject to be more deliberate, and to search more carefully, following prior cuing than under matched control conditions.

Currently, one can draw on considerable data and theory from memory research on pigeons and conclude that, under several conditions, delayed conditional discrimi- 
nations like those used in our language-like task with sea lions are for the most part mediated by prospective rather than retrospective coding. Thus, animal subjects are more apt to remember a representation of the correct comparison stimulus than to retain a memory of the conditional cue (see Honig \& Thompson, 1982; Roitblat, 1982; and Wasserman, 1986; but cf. Urcuioli \& Zentall, 1986). Rocky's orienting behavior is particularly cogent in this regard. Following one, two, or three gestural signals designating an object, Rocky searches the pool and momentarily stops to look at individual objects (see Figure 1). From observing this behavior pattern repeatedly, it becomes clear that after integrating modifier and object signs as conditional cues, Rocky compares objects according to brightness, size, and shape (Schusterman \& Krieger, 1984, 1986). Under most baseline and experimental conditions, the last object Rocky points at before she restations to receive the succeeding gestural cue is almost invariably the object she selected subsequently when she was released from station. We view these orientations as anticipatory choices during single-object and relational commands. Such orientations occurring almost immediately following the object sign (cf. Schusterman \& Krieger, 1986) appear to aid the sea lion in remembering where an object is located, and they indicate that sea lions, or at least the sea lion Rocky, transform the gestural signal to a representation of a comparison (or choice) stimulus early in the retention interval (see Roitblat, 1982). If we assume that the sea lions were coding the gestural signals prospectively, then, when there was active maintenance of a GI representation due to prior cuing, the enhanced GI representation should have been subject to less interference from subsequent search and selection activities, such as search for and selection of the TI.

We conclude from our present experiment that priming cues are effective in decreasing the deleterious effects of retroactive interference on the working memory of California sea lions, and we interpret this finding as broadly supporting the notion put forth about a decade ago by Spear (1981) that "learning" variables "depend on their particular interaction with how the learning is expressed, or in other words, the circumstances of memory retrieval"' (p. 373).

\section{REFERENCES}

D'Amato, M. R. (1973). Delayed matching and short-term memory in monkeys. In G. H. Bower (Ed.), The psychology of leaming and motivation: Vol. 7. Advances in research and theory (pp. 227-269). New York: Academic Press.

Gisiner, R., \& Schusterman, R. J. (1992). Sequence, syntax and semantics: Responses of a language-trained sea lion (Zalophus californianus) to novel sign combinations. Journal of Comparative Psychology, 106, 78-91.

Herman, L. M. (1986). Cognition and language competencies of bottlenose dolphins. In R. J. Schusterman, J. A. Thomas, \& F. G. Wood (Eds.), Dolphin cognition and behavior: $A$ comparative approach (pp. 221-252). Hillsdale, NJ: Erlbaum.

HoNIG, W. K., \& JAMES, P. H. R. (1971), Animal memory. New York: Academic Press.

Honig, W. K., \& Thompson, R. K. R. (1982). Retrospective and prospective processing in animal working memory. In G. H. Bower
(Ed.), The psychology of learning and motivation (Vol. 16, pp. 239283). New York: Academic Press.

Kamil, A. C., \& RoItblat, H. L. (1985). The ecology of foraging behavior: Implications for animal learning and memory. Annual Review of Psychology, 36, 141-170.

KENDRICK, D. R., \& Rilling, M. E. (1986). AIM: A theory of active and inactive memory. In D. R. Kendrick, M. E. Rilling, \& M. R. Denny (Eds.), Theories of animal memory (pp. 129-152). Hillsdale, NJ: Erlbaum.

Kendrick, D. R., Rilling, M. E., \& DenNy, M. R. (Eds.) (1986). Theories of animal memory. Hillsdale, NJ: Erlbaum.

RILLING, M. E., \& NeIworTH, J. J. (1986). Comparative cognition: A general processes approach. In D. F. Kendrick, M. E. Rilling, \& M. R. Denny (Eds.), Theories of animal memory (pp. 19-33). Hillsdale, NJ: Erlbaum.

RoItBLAT, H. L. (1982). The meaning of representation in animal memory. Behavioral \& Brain Sciences, 5, 353-406.

Roitblat, H. L., Bever, T. G., Terrance, H. S. (Eds.) (1984). Animal cognition. Hillsdale, NJ: Eribaum.

RoItblat, H. L., \& Von Fersen, L. (1992). Comparative cognition representations and processes in learning and memory. Annual Review of Psychology, 43, 671-710.

Schusterman, R. J., \& Gisiner, R. (1988). Artificial language comprehension in dolphins and sea lions: The essential cognitive skills. Psychological Record, 38, 311-348.

SChusterman, R. J., \& Gisiner, R. (1989). Please parse the sentence: Animal cognition in the procrustean bed of linguistics. Psychological Record, 39, 3-18.

Schusterman, R. J., Gisiner, R., Grimm, G. K., \& Hanggi, E. B. (1993). Behavior control by exclusion and attempts at establishing semanticity in marine mammals using match-to-sample paradigms. In H. Roitblat, L. Herman, \& P. Nachtigall (Eds.), Language and communication: Comparative perspectives (pp. 249-275). Hillsdale, NJ: Erlbaum.

Schusterman, R. J., \& Krieger, K. (1984). California sea lions are capable of semantic comprehension. Psychological Record, 34, 3-23.

SChusterman, R. J., \& Krieger, K. (1986). Artificial language comprehension and size transposition by a California sea lion (Zalophus californianus). Journal of Comparative Psychology, 100, 348-355.

SHETTLEWORTH, S. J. (1990). Spatial memory in food-storing birds. Philosophical Transactions of the Royal Society: Series B, 329, 143-151.

SPEAR, N. E. (1981). Extending the domain of memory retrieval. In N. E. Spear \& R. R. Miller (Eds.), Information processing in animals (pp. 341-378). Hillsdale, NJ: Erlbaum.

SPEAR, N. E., \& MILLER, R. R. (EDs.) (1981). Information processing in animals: Memory mechanisms. Hillsdale, NJ: Erlbaum.

Spear, N. E., Miller, J. S., \& Jagielo, J. A. (1990). Animal memory and learning. Annual Review of Psychology, 41, 169-211.

Tulving, E. (1974). Cue-dependent forgetting. American Scientist, 62 , 74-82.

UrCuioli, P. J., \& Zentall, T. R. (1986). Retrospective coding in pigeons' delayed matching-to-sample. Journal of Experimental Psychology: Animal Behavior Processes, 12, 69-77.

Wasserman, E. A. (1986). Prospection and retrospection as processes of animal short-term memory. In D. F. Kendrick, M. E. Rilling, \& M. R. Denny (Eds.), Theories of animal memory (pp. 53-75). Hillsdale, NJ: Erlbaum.

Weinberger, N. H., McGaugh, J. L., \& Lynch, G. (Eds.) (1985). Memory systems of the brain. New York: Oxford University Press.

Wright, A. A., Urcuioli, P. J., \& SANDS, S. F. (1986). Proactive interference in animal memory. In D. R. Kendrick, M. E. Rilling, \& M. R. Denny (Eds.), Theories of animal memory (pp. 101-125). Hillsdale, NJ: Erlbaum.

Wright, A. A., Urcuioli, P. J., Sands, S. F., \& Santiago, H. C. (1981). Interference of delayed matching to sample in pigeons: Effects of interpolation at different periods within a trial and stimulus similarity. Animal Learning \& Behavior, 9, 595-603.

(Manuscript received June 12, 1992; revision accepted for publication February 8, 1993.) 